\title{
A case of plagiarism: Dănuț Marcu
}

\section{Editorial note}

\author{
Denis Bouyssou $^{1 \star}$, Silvano Martello ${ }^{2 \star \star}$, Frank Plastria ${ }^{3 \star \star \star}$ \\ 1 CNRS \\ 2 Università di Bologna \\ 3 Vrije Universiteit Brussel
}

The date of receipt and acceptance will be inserted by the editor

On October 2002, Dănut Marcu from Bucharest submitted to our journal a short paper, entitled "Some results on the independence number of a graph". It can be downloaded from our web page: http://homepages . vub . ac.be/ ${ }^{\sim}$ fouror/. The competent Area Editor sent it out for refereeing. The first referee returned a report asking for revision, while the second one wrote:

\footnotetext{
Yesterday I started reading the paper by Dănuţ Marcu that you sent me. I liked it: the results and proofs were not great but very neat. At the same time I was surprised that he gives too few references on such an important subject, and had a feeling that I had seen something like this somewhere. So today I started checking and 15 minutes ago I discovered that the paper is a very slightly modified copy of the paper by J. B. Shearer: "The independence number of dense graphs with large odd girth" ( The Electronic Journal of Combinatorics 2 (1995), http://www. combinatorics.org/).

This is the first time I discovered a $100 \%$ plagiarism in math publications. Then it struck me that recently I heard about a plagiarist in a letter from a well known mathematician. I found it - it was about Marcu!!! Please let the fact be well known in OR community. Marcu has to get rejected no matter where he sends his or "his" papers.
}

A letter was attached from the well-known mathematician, stating that Marcu is a notorious plagiarist, and that he became aware of this several

* LAMSADE, Université Paris Dauphine, Place du Maréchal de Lattre de Tassigny, F-75775 Paris Cedex 16, France, tel: +331440548 98, fax: +331 440540 91, e-mail: 4or@lamsade.dauphine.fr.

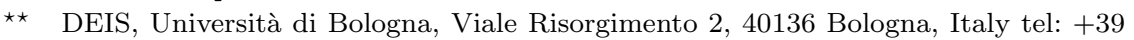
051 2093022, fax: +39051 2093073, e-mail: 4or@deis.unibo.it.

$\star \star \star$ MOSI-Dept. of Mathematics, Operational Research, Statistics and Information Systems, for Management, Vrije Universiteit Brussel, Pleinlaan 2, B-1050 Brussels, Belgium, tel: +32 2 6293609, fax: +32 2 6293690, e-mail: 4or.be@vub.ac.be. 
years ago when he published a result in a reputable British journal almost simultaneously as the true authors published their paper in another good journal. Then he learned that Marcu had also copied another author, who objected in a letter: Marcu responded with a childish drawing indicating that he is out of reach.

By googling on the Internet we discovered other interesting facts on Dănut Marcu. In the list of papers at the home page of Paul Renteln (California State University, San Bernardino, see http://physics.csusb.edu/ prenteln/) you find:

15. P. Renteln, "On the Chromatic Number of the Complement of a Class of Line Graphs", Ars Combinatoria 67 (2003) 33-36.

A very odd thing has happened. A fellow by the name of Dănuţ Marcu has plagiarized my paper in its entirety! The first two pages of his paper, entitled "A Note on the Chromatic and Independence Number of a Graph" in Studia Universitatis Babes-Bolyai Informatica, Vol XLVIII, Number 2, 2003, pp. 11-16, are basically just a rewording of my paper, down to the details of the proofs. Apparently this is not the first time this has happened - he has been plagiarizing papers for years and passing them off as his own. Unfortunately, many of his papers fool both the referees and the journals. If you have MathSciNet access, you can check out the reviews of some of his other papers, many of which confirm his disgraceful fraudulent behaviour. (Thanks to Professor Jerrold W. Grossman of Rochester University for uncovering Marcu's latest deception and for informing me about the situation.)

(Note: links to Dănuţ Marcu appear now to have been removed from the web site of MathSciNet.)

In Volume XLIX, Number 1 (2004) of Studia Universitatis Babes-Bolyai Informatica, the Editors say, at page 112 (downloadable from the Journal's web site, http://www.cs.ubbcluj.ro/〜studia-i):

\section{APOLOGY ON PLAGIARISM PAPERS} THE EDITORS

Since the preceding issue has been sent to print we have found out, and have been informed by more interested readers that the following papers are plagiates:

- D. Marcu, The Chromatic Number of Triangle-Free Regular Graphs, Studia Universitatis Babes-Bolyai Series Informatica, 47 (1), 2002, p. 54-56.

- D. Marcu, A Note on the Chromatic Number of a Graph, Studia Universitatis Babes-Bolyai Series Informatica, 47 (2), 2002, p. 105-106.

- D. Marcu, A Note on the Chromatic and Independence Number of a Graph, Studia Universitatis Babes-Bolyai Series Informatica, 48 (2), 2003, p. 11-16.

... After a careful consideration, we have decided to retract the papers under scrutiny; the papers will be marked as such on the journal web page. As we have lost the confidence in Mr. Dănuţ Marcu, the author of these plagiates, we have decided to ban Mr. Marcu from publishing in our journal. We are apologizing to the international scientific community for this situation.

(The three mentioned papers no longer appear in the journal's web site.)

In Volume 11, Number 3(33), 2003 of the Computer Science Journal of Moldova (see http: //www.math.md/imi-site/journals/csjm/index) you 
find:

On behalf of "Computer Science Journal of Moldova" editorial board

The article of D. Marcu "Note on the n-cycles and their achromatic numbers" was published in the Number 3(30), Volume 10, 2002 of our journal. Later it became clear that the said article is a plagiarism of the Prof. Francette Bories work published in 1975.

The editorial board of our journal thanks Prof. Jerrold W. Grossman and Prof. Vitaly Voloshin for the assistance rendered in the disclosure of that fact. We present our apologies to the readers.

In the Graph Theory White Pages you can find a page dedicated to Dănuţ Marcu (http://www1.cs.columbia.edu/ sanders/graphtheory/ people/search.html, input "Marcu" or "Marcu, Danut", case sensitive), from which it results that he has published eighty papers in the period 1990-2003.

The list of publications "by" Dănuţ Marcu can also be downloaded from our web page, http://homepages.vub.ac.be $/{ }^{\sim}$ fouror/. Maybe colleagues working on Graph Theory could be interested in checking these results. One interesting fact immediately arises: The second paper in this list is

[2.] "Some results on the independence number of a graph.", J. Indian Inst. Sci. 83 (2003) p. 95-97.

showing that, unfortunately, he succeeded in publishing the plagiarism that had been rejected by $4 O R$. The published paper, that can be downloaded from the web site of the Journal of the Indian Institute of Science (http: //journal.library.iisc.ernet.in/), is unchanged with respect to his submission to our journal, with one exception. Dănuț Marcu, a very nice person indeed, added an acknowledgment section, reading: "I wish to express my gratitude to the referees for their useful suggestions and interest concerning this paper."

Just like Studia Universitatis Babes-Bolyai Informatica, we have decided to ban Mr. Dănuţ Marcu from publishing in $4 O R$, and hope fellow Editors will do the same. 